\title{
RELACIÓN ENTRE LAS HABILIDADES METALINGUISTICAS Y LA MEMORIA EN NIÑOS DE PRIMER Y SEGUNDO GRADO DE PRIMARIA DE LIMA METROPOLITANA
}

\author{
METALINGUISTIC ABILITIES AND MEMORY IN CHILDREN FIRST \\ AND SECOND GRADE PRIMARY FROM METROPOLITAN LIMA
}

\author{
María Matalinares C., Gloria Diaz, A. Juan Yaringaño L., Lidia Sotelo L., Noemi Sotelo L., Gloria Diaz A. \\ Alejandro Dioses Ch., Rodrigo Ramos C., Yizza Medina R., Mary Pezua V., Raúl Muratta E., Cecllia Pareja F. \\ MaRIA SILVA B. \\ Universidad Nacional Mayor de San Marcos, Lima, Perú \\ (RECIBIDO EL 25/09/2011 - ACEPTADO 02/12/ 2011)
}

\begin{abstract}
RESUMEN
La investigación tuvo como objetivo establecer si existía o no relación entre las habilidades metalinguisticas y la memoria en estudiantes de primer y segundo grado de primaria de Lima Metropolitana. Se evaluó a 164 niños de primer y segundo grado de primaria, de ambos sexos, cuyas edades fluctuaban entre los 6 y 7 años de edad, a quienes se aplicó el Test de Habilidades Metalinguisticas propuesta por Gómez,J. Valero, R. Buades,A. y Pérez. y adaptado a nuestra realidad por Panca (2000) y el Sub Test de memoria de digitos de la Escala de Wecshler para niños (WISC III). Los resultados mostraron que existe correlación entre las habilidades metalinguisticas y la memoria de los niños. Se halló correlación positiva entre segmentación silábica, supresión silábica, detección de rimas, unir fonemas y contar fonemas con la retención de dígitos en orden progresivo, y correlación negativa entre la adición silábica y retención de dígitos en orden progresivo. También se halló correlaciones positivas entre la segmentación silábica, supresión silábica, aislar fonemas, unir fonemas y contar fonemas con la retención de dígitos en orden inverso. Se encontraron diferencias en las habilidades metalingüísticas y en la retención de dígitos en orden progresivo e inverso, según el grado de estudio.
\end{abstract}

Palabras clave: habilidades metalinguisticas, memoria, estudiantes de primaria, conciencia fonológica.

\begin{abstract}
This research had as purpose to establish a relationship between metalinguistic abilities and memory in students of first and second grade in Metropolitan Lima. A sample of 164 children were assessed, between first and second grades of primary school, both of sexes, whose ages ranged between 6 and 7 years olds, who applied the Metalinguistic Abilities Test by Gomez, Valero, Buades and Perez (adapted to our reality by Panca, 2000) and Digit Span Subtest of the Wechsler Intelligence Scale for Children (WISC III). The results
\end{abstract}


Relación entre las Habilidades Metalinguisticas y la Memoria en Niños de Primer y Segundo Grado de Primaria de Lima Metropolitana

showed a correlation between metalinguistic abilities and memory of children. A positive correlation was found between syllable segmentation, syllable deletion, rhyme detection, join the phonemes and phoneme counting with retention of digits in forward order, and negative correlation between syllable addition and retention of digits in progressive order. Also it was found positive correlations between syllable segmentation, syllable deletion, isolate phonemes, join the phonemes and count phonemes with retention of digits in reverse order. There were differences in metalinguistic abilities and retention of digits in forward and reverse order, depending on the grade of study.

Key Words: Metalinguistic abilities, memory, primary school students, phonological awareness.

\section{INTRODUCCION}

El aprendizaje lector ha sido investigado desde diferentes perspectivas a lo largo del tiempo y tres son los enfoques más aceptados: el Modelo Perceptivo Motor propuesto por Vidal y Majón (2000) que lo define como un proceso de traducción de signos gráficos en sus correspondencias sonoras, en relación a procesos lingüísticos y de pensamiento del lenguaje oral; el Modelo Madurativo considera que para que una persona aprenda específicamente la lectura requiere de madurez y del desarrollo de habilidades básicas para su aprendizaje (visuales, motrices, lingüísticas, etc.) aunque aún no se ha establecido con precisión cuáles son esos factores.

Por último, el modelo psicolingüístico sostiene que la enseñanza de la educación lectora debería abandonar los supuestos de los modelos madurativos, para entender que los procesos lectores son aprendizajes que en sí mismos posibilitan la "maduración" para el alumnado. En este sentido, Cuetos (1999) asume que se disponen de dos vías para acceder al significado de las palabras escritas: la léxica y la fonológica; por la primera vía se podrían leer todo tipo de palabras, conocidas, pero por la vía fonológica se podrían leer todo tipo de palabras conocidas o no, que siguiesen una serie de reglas grafo-fonéticas del alfabeto español (Vidal y Manjón, 2000). Es importante señalar que la conciencia fonológica es uno de los cuatro tipos generales de conocimiento metalingüístico, más relacionado con el aprendizaje de la lectura y la escritura.

La conciencia fonológica está referida al conocimiento de las unidades de sonido (fonemas) usados en un lenguaje, incluyendo la habilidad de oír fonemas separados. Mattingly (1972), Wagner y Torgese (1987) la definen como conciencia y acceso a la fonología del lenguaje de cada uno. Algunas veces es llamada conciencia fonémica. Este conocimiento incluye el reconocimiento de que las palabras están compuestas de unidades de sonido y que las unidades de sonido pueden ser combinadas para formar palabras (Mayer 2002). Para Mann (1989) es la conciencia explícita de la existencia de unidades fonológicas tales como los fonemas, las sílabas. Turner y Rol (1991) la definen como la capacidad para ejecutar operaciones mentales sobre el producto del mecanismo de percepción del habla. Para Gimeno (1993) conciencia fonológica es el nivel de comprensión explícita o implícita que posee el sujeto respecto a la relación que hay entre las letras del alfabeto y los sonidos y/o fonemas que representan. Jiménez y Ortiz (1995) afirman que la conciencia 
fonológica se refiere a la toma de conciencia de cualquier unidad fonológica del lenguaje hablado (Amaiz y Ruiz, 2001). De este modo se hace énfasis en las habilidades metalingüísticas, como la capacidad que posee el niño de la estructura y funciones de su lengua, permitiéndole diferenciar la naturaleza de las palabras y frases en los ámbitos fonológico, semántico, sintáctico y pragmático.

Ahora bien, investigaciones realizadas en el extranjero como la de Helfgot (1976) citado por Molina (1991) comprueban que el mejor predictor del éxito en el aprendizaje de la lectura era la capacidad de segmentación de los constituyentes fonemáticos de una palabra cuando los niños estaban en preescolar. Obteniendo una correlación alta entre dicha capacidad y los resultados en lectura al finalizar el primer año de aprendizaje. Liberman (1977) citado por Calero y otros, (1999) encontró una correlación positiva entre la habilidad de manipular segmentos orales y el rendimiento lector.

En esta misma linea de investigacion, Pennintong, Groisser y Welsh (1993) citado por Mayer (2002) encontraron que los niños con dificultad para aprender a leer en la escuela primaria, a menudo carecen de habilidades para la conciencia fonológica. Stanovich y col. (1989), encontraron que en la raìz de los problemas lectores existía un déficit en el procesamiento fonológico el cual se desarrolla en forma independiente del resto de las funciones intelectuales (Canales,2003). Maldonado (1990) citado por Jiménez y Ortiz (2000) encontraron que los niños con rendimiento lector óptimo muestran mejores habilidades para analizar los sonidos y las palabras del habla concluyendo que las habilidades de reflexión sobre el habla son requisito de lectura ya que ante igual edad lectora la diferencia está en su habilidad de manipular segmentos del habla. Warner y Torgesen (1987) encontraron que la conciencia fonológica y la lectura están relacionadas independientemente de las habilidades cognitivas generales (Mayor, 2002). Gonzales y Romero (1999) encontraron que la producción fonológica es una variable predictiva de la lectura entre los seis y los ocho años, siendo la exactitud lectora la variable que mejor explica la producción fonológica entre estas edades. Condemarin (1989) encontró que las variables que tenían mayor incidencia en el nivel lector y que mejor discriminaban los grupos eran la discriminación de fonemas, de consonantes y la percepción y memoria de secuencias de fonemas.

En el Perú Rodríguez (2003) realizó un estudio comparativo entre las habilidades metalingüísticas en niños de 3er grado primaria y encontró que los alumnos de Colegios Particulares se encuentran en un nivel de desarrollo adecuado en todos los subtest del test de Habilidades Metalingüísticas con respecto a los alumnos de Colegios Estatales. Matalinares y Diaz (2007) realizaron una investigación cuyo propósito fue establecer si existe relación entre las habilidades metalinguísticas y la comprensión en niños de primer grado de las ciudades de Lima y Huancayo. Para ello evaluó a 155 estudiantes que cursaban el primer grado de primaria, de 6 años de edad, de ambos sexos, procedentes de diversos centros educativos estatales de las ciudades de Lima y Huancayo, a quienes aplicó el Test de Habilidades Metalinguísticas (THM) propuesto por Gómez, Valero, Buades y Pérez y adaptado 
a nuestra realidad por Panca (2003) y el Sub test de Comprensión de la Escala de Weschler para niños (WISC-R). Los resultados mostraron que existe correlación altamente significativa, positiva y de grado moderado entre las habilidades metalingüísticas y la comprensión. Al comparar las muestras de Lima y Huancayo no se encontraron diferencias significativas en las habilidades metalingüísticas, ni en comprensión. Cuando se compara el puntaje general en habilidades metalingüísticas y comprensión entre hombres y mujeres no se hallaron diferencias significativas.

Ahora bien, respecto de la memoria y se puede definir como la capacidad de retener, o como un proceso de almacenamiento y recuperación de la información en el cerebro, básico en el aprendizaje y en el pensamiento. Según Baddeley (1992) la memoria a corto plazo es la que guarda y procesa durante breve tiempo la información que viene de los registros sensoriales y actúa sobre ellos y también sobre otros. Esta memoria nos capacita para recordar la información pero, al ser limitada y susceptible de interferencias, nos permite estar siempre abiertos a la recepción de nueva información. Baddeley y Hitch (1974) estudiaron en profundidad cómo funciona la memoria de trabajo. Ellos demostraron cómo funciona la memoria de trabajo. Así pidieron a un grupo de sujetos que realizaran una tarea que exigiera la utilización de gran parte de la capacidad de la memoria de trabajo (amplitud de memoria de dígitos). En el mismo momento, le pidieron que realizara otra tarea que supuestamente dependía también de la memoria de trabajo (una tarea de aprendizaje). Los resultados mostraron que el tiempo necesario para realizar la tarea de aprendizaje aumentó de forma sistemática en función del aumento de la carga de memoria impuesta por la tarea de repetición de dígitos. Baddeley y Hitch explicacron que la memoria a corto plazo, en vez de ser una memoria unitaria, estaba formada por varios elementos. Propusieron la existencia de un ejecutivo central que desempeñara el papel del control atencional y dos sistemas subsidiarios, el bucle articulatorio y la agenda visoespacial. El primero sería el encargado de conservar transitoriamente la información auditiva y estaría relacionado con el tratamiento de los contenidos del lenguaje oral, mientras que el segundo sistema sería el encargado de la conservación transitoria de la información visoespacial y el procesamiento de las imágenes mentales. El sistema ejecutivo central tiene una capacidad limitada y su función es supervisar y coordinar los otros subsistemas. El bucle o lazo fonológico, es un subsistema especializado en el almacenamiento temporal de la información basada en el lenguaje. La agenda viso-espacial, es la encargada del almacenamiento temporal de la información visual y espacial (Ballesteros, 1999).

Siegel (1994) citado por Gutierrez, Garcia Madruga, Elosua, Luque y Gárate (2002) desarrolló una investigación longitudinal de la memoria operativa desde los 6 años hasta la edad adulta, utilizó distintos tipos de tareas: memoria a corto plazo, memoria operativa, de reconocimiento de palabras y de comprensión lectora. Los resultados mostraron un crecimiento gradual en el desarrollo de la memoria operativa desde los 6 hasta los 19 años y una disminución tambien gradual a partir del final de la adolescencia, con una mayor caida a partir de los 65 y 70 años. Towse y Hitch (1995) citados por Gutierrez, Garcia Madruga, Elosua, Luque y 
Gárate (2002) sugieren la posibilidad de que con el desarrollo evolutivo las tareas verbales complejas se hagan menos dependientes del lazo articulatorio, y más de la capacidad de compartir recursos en el ejecutivo central. De acuerdo con Ellis y Sinclair (1996), la memoria de trabajo está fuertemente comprometida en la adquisición del lenguaje, debido a que mayoritariamente consiste en aprender secuencias.

Al considerar los sistemas de memoria, Sáiz y Baqués (1999) estudiaron la relación entre dos subsistemas de la memoria de trabajo (bucle fonológico y agenda visoespacial) y el rendimiento en cálculo con una muestra de 94 niños españoles de 7-8 años. Los investigadores administraron dos pruebas de cálculo y seis medidas simples de memoria de trabajo (de contenido verbal, numérico y espacial) de la «Batería de Tests de Memoria de Treball» de Pickering, Baqués y Gathercole (1999), y dos pruebas visuales complementarias. Los resultados mostraron una correlación importante entre las medidas de contenido verbal y numérico y el rendimiento en cálculo. No hallaron relación con las medidas espaciales. Concluyeron que en escolares españoles existe una relación importante entre el bucle fonológico y el rendimiento en tareas de cálculo. En cambio, el rol de la agenda viso-espacial es nulo. Gutierrez et al (2002) investigaron la infuencia de la memoria operativa en las habilidades de comprensión lectora. Los resultados mostraron entre otras cosas que los sujetos de mayor edad obtenían puntuaciones más altas que los jóvenes, lo que se explica por la mayor capacidad de la memoria operativa. Los autores explicaron que la memoria operativa de dígitos tiene un nivel de exigencia de procesamiento intermedio entre las pruebas de amplitud de palabras y la de amplitud lectora.

Pino y Bravo (2005) examinaron la relación entre el reconocimiento visual-ortográfico, la percepción y la memoria visual con la lectura inicial. Trabajaron con 105 niños de primer grado básico. Los resultados mostraron que la percepción y la memoria visual son buenos predictores de la lectura inicial.

Garcia, Canet y Andrés (2010) en Mar de Plata argentina exploraron las relaciones entre el desarrollo de la flexibilidad cognitiva y de la memoria de trabajo en un grupo de niños de 6 a 9 años de edad de una escuela de gestión privada. Los resultados mostraron una correlación significativa entre la flexibilidad cognitiva y la memoria de trabajo, pero sólo en la tarea de dígitos en progresión. Los niños de 9 años mostraron mejorías significativas respecto de los niños de 6 años, enfatizando que el período clave para el desarrollo de estas capacidades es entre los 6 y los 9 años de edad. Introzzi, Canet, y Andrés (2010) investigaron el desarrollo de estrategias de memoria en niños de en niños entre 5 y 12 años de edad. Los resultados mostraron que a pesar de que no se registra un incremento significativo en el uso de estrategias vinculado a la edad, cuando los niños implementan estos recursos, su aprendizaje y recuerdo parecen beneficiarse.

Crespo y Alvarado (2010) relacionaron la conciencia meta pragmática con la memoria de trabajo en niños de 8 y 9 años encontrando que el incremento de la conciencia meta pragmática no depende solamente del desarrollo lingüístico de los individuos, sino también de una maduración de los sistemas cognitivos involucrados en el almacenamiento y procesamiento de la información. 
En el Perú investigadores como Dioses (2004) relacionó la memoria auditiva inmediata con las dificultades en el aprendizaje de la ortografía en niños que cursan el quinto y sexto grado de educación primaria. Los resultados mostraron entre otros aspectos que existe relación significativa e inversa entre la memoria auditiva inmediata y la cantidad de errores ortográficos cometidos. Matalinares, Dioses, Arenas, Diaz, Chávez, Yaringaño y Suárez (2007) estudiaron la relación entre Lenguaje comprensivo y memoria auditiva inmediata en estudiantes de $5 .^{\circ}$ y $6 .^{\circ}$ grado de primaria de zona rural y urbana de Lima. Los resultados mostraron que ambas variables se encontraban correlacionadas. Yaringaño (2009) estudio la relación entre la memoria auditiva inmediata y la comprensión lectora en alumnos de quinto y sexto grado de primaria: los resultados mostraron que existe relación entre estas dos variables.

\section{HIPOTESIS GENERAL}

Las habilidades metalingüísticas se relacionan positivamente con la memoria de los niños que cursan el primer grado de primaria en Lima metropolitana.

\section{HIPOTESIS ESPECIFICAS}

1. Las dimensiones de segmentación silábica, supresión silábica, detección de rimas, adición silábica, aislar fonemas, unir fonemas y contar fonemas se relacionan positivamente con la retención de dígitos en orden progresivo.

2. Las dimensiones de segmentación silábica, supresión silábica, detección de rimas, adición silábica, aislar fonemas, unir fonemas y contar fonemas se relacionan positivamente con la retención de dígitos en orden inverso.

3. Existen diferencias significativas en las dimensiones de la habilidades metalinguisticas según el grado de estudio.

4. Existen diferencias significativas en la retencion de digitos directo e inverso según el grado de estudio.

\section{MÉTODO}

Para la realización de la presente investigación se empleó el método descriptivo con un diseño correlacional y comparativo. Se evaluara a 164 estudiantes de primer grado y segundo de primaria, de ambos sexos, cuyas edades fluctuan entre los 6 y 7 años procedentes de centros educativos estatales de Lima Metropolitana.

Tabla A

Muestra de sujetos según sexo y edad

\begin{tabular}{cccc}
\hline & \multicolumn{3}{c}{ Sexo } \\
\cline { 2 - 4 } Grado de estudio & Femenino & Masculino & Total \\
\hline $1^{\mathrm{o}}$ & 73 & 24 & 97 \\
$2^{\mathrm{o}}$ & 36 & 31 & 67 \\
Total & 109 & 55 & 164 \\
\hline
\end{tabular}


Se observa de la Tabla A que la muestra está constituida por 164 niños. En el caso de los niños de sexo masculino 24 pertenecen al $1^{\circ}$ de primaria y 31 al $2^{\circ}$ de primaria, en las mujeres 73 pertenecen al $1^{\circ}$ de primaria y 36 al $2^{\circ}$ de primaria.

La variables principales del estudio fueron: Habilidades Metalinguísticas y la memoria .

Tecnica e Instrumentos: Dado el carácter de los fenómenos a estudiar se utilizarán la técnica psicometríca y de observación indirecta. Los instrumentos a utilizarse son:

EI test de Habilidades Metalingúisticas (THM) propuesta por Gómez,J. Valero ,R. Buades,A. y Pérez. y adaptado a nuestra realidad por Panca (2000). Esta Prueba consta de 102 itemes divididos en siete sub test: segmentación silábica, supresión silábica, detección de rimas, adición silábica, aislar fonemas, unir fonemas y contar fonemas. La administración es en forma individual en un tiempo aproximado de 30 minutos, con instrucciones precisas para cada uno de los subtest, donde el niño debe responder verbalmente luego de habersele dado las demostraciones. la Validez del test en nuestro medio fue de contenido, a traves del criterio de jueces. Se La validez de construcción empleo el anáslisis factorial exploratorio, siendo la varianza exploicada de 47,69. La medida de adecuación del muestreo de Kaiser-Meyeer-Olkin de $=.83$. Test de esfericidad de Barlett de 438.84 a un nivel de sigbnificación de 0.001. La confiabilidad inicial utilizó el método de las dos mitades empleando el coeficiente de Spearman arrojó 0.95 ycon un error típico de 0.16. Panca (2000) la confiabilidad mediante la técnica de dos mitades usando la formula de Kuder Richardson 20, se obtuvo una confiabilidad de 0,81 y con la técnica de consistencia interna con el alfa de Cronbach de 0.8141 .

El Sub Test de retencion de digitos de la Escala de Wecshler para niños (WISC III) Esta Escala planteada por David Weschler es una prueba que está respaldada por una amplia variedad de estudios que han confirmado su utilidad y confiabilidad. Se usó aquí la adaptación de De la Cruz y Cordero (2001).En nuestro medio se han realizado estudios para adaptar los elementos del test y obtener normas locales que permiten su uso de manera confiable. En el sub Test de memoria Dígitos, la tarea del sujeto es repetir una serie de dígitos que se le presentan oralmente. Evalúa la memoria auditiva inmediata y la capacidad de atención y resistencia a la distracción. La aplicación es individual.

\section{RESULTADOS}

A continuación se presentan los estadísticos descriptivos e inferenciales obtenidos en el análisis de los datos obtenidos.

\section{Resultados Descriptivos}

Tabla 1. Resultados descriptivos en retención de dígitos

\begin{tabular}{lcccc}
\hline & $\mathrm{N}$ & Media & Mediana & Desv. típ. \\
\hline Dígitos Directo & 164 & 5,70 & 6,00 & 2,103 \\
Dígitos Inverso & 164 & 3,99 & 4,00 & 1,427 \\
Retención de Dígitos & 164 & 9,68 & 9,00 & 3,206 \\
\hline
\end{tabular}


Relación entre las Habilidades Metalinguisticas y la Memoria en Niños de Primer y Segundo Grado de Primaria de Lima Metropoltana

De acuerdo con la Tabla 1, los alumnos obtienen en retención de dígitos directo un promedio de 5,70, en retención de dígitos inverso 3,99, y en retención de dígitos total un promedio de 9,68 .

Tabla 2. Resultados descriptivos en habilidades metalingüísticas

\begin{tabular}{ccccc}
\hline & $\mathrm{N}$ & Media & Mediana & Desv. típ. \\
\hline Segmentación Silábica & 164 & 0,9247 & 1,00 & 0,199 \\
Supresión Silábica & 164 & 0,8540 & 1,00 & 0,238 \\
Detección de Rimas & 164 & 0,8645 & 1,00 & 0,255 \\
Adición Silábica & 164 & 0,9366 & 1,00 & 0,201 \\
Aislar Fonemas & 164 & 0,8718 & 1,00 & 0,238 \\
Unir Fonemas & 164 & 0,7460 & 0,80 & 0,264 \\
Contar Fonemas & 164 & 0,7415 & 0,80 & 0,255 \\
THM & 164 & 5,9379 & 6,34 & 1,309 \\
\hline
\end{tabular}

De acuerdo con la Tabla 2, los alumnos obtienen mayor promedio en segmentación silábica un promedio de 0,92 , y lo menores promedio en unir fonemas $0,75 \mathrm{y}$ en contar fonemas 0,74. El promedio en habilidades metalingüísticas 5,94.

Tabla 3. Niveles de habilidades metalingüísticas

\begin{tabular}{lccc}
\hline NIVEL & $\mathrm{N}$ & Frecuencia & Porcentaje \\
\hline DEFICIENTE & 164 & 5 & $3,0 \%$ \\
INTERMEDIO & 164 & 35 & $21,3 \%$ \\
AVANZADO & 164 & 124 & $75,6 \%$ \\
Total & 164 & 164 & $100,0 \%$ \\
\hline
\end{tabular}

De acuerdo con la Tabla 3, el 3,0\% de los alumnos presentan un nivel Deficiente en habilidades metalingüísticas, el $21,3 \%$ de los alumnos presentan un nivel Intermedio, y el 75,6\% presentan un nivel Avanzado, siendo este último grupo el mayoritario.

Tabla 4. Resultados descriptivos en memoria de dígitos según grado

\begin{tabular}{lccccc}
\hline & Grado & $\mathrm{N}$ & Media & Mediana & Desv. típ. \\
\hline \multirow{2}{*}{ Dígitos Directo } & $1^{\mathrm{o}}$ & 97 & 4,48 & 4 & 1,251 \\
& $2^{\mathrm{o}}$ & 67 & 7,45 & 7 & 1,836 \\
\multirow{3}{*}{ Dígitos Inverso } & $1^{\mathrm{o}}$ & 97 & 3,23 & 3 & 1,026 \\
& $2^{\mathrm{o}}$ & 67 & 5,09 & 5 & 1,190 \\
Memoria Dígitos & $1^{\mathrm{o}}$ & 97 & 7,71 & 8 & 1,865 \\
& $2^{\mathrm{o}}$ & 67 & 12,54 & 12 & 2,519 \\
\hline
\end{tabular}


De acuerdo con la Tabla 4 , los alumnos de $2^{\circ}$ grado obtienen mayor promedio en retención de dígitos directo 4,48 en retención de dígitos inverso 5,09 , y en retención de dígitos 12,54, a compararlos con los alumnos de $1^{\circ}$ primaria.

Tabla 5. Resultados descriptivos en habilidades metalingüísticas según grado

\begin{tabular}{cccccc}
\hline & Grado & $\mathrm{N}$ & Media & Mediana & Desv. típ. \\
\hline \multirow{2}{*}{ Segmentación Silábica } & $1^{\mathrm{o}}$ & 97 & 0,8758 & 1,00 & 0,247 \\
& $2^{\mathrm{o}}$ & 67 & 0,9955 & 1,00 & 0,021 \\
\cline { 2 - 6 } Supresión Silábica & $1^{\mathrm{o}}$ & 97 & 0,7771 & 0,83 & 0,275 \\
& $2^{\mathrm{o}}$ & 67 & 0,9652 & 1,00 & 0,093 \\
\cline { 2 - 6 } Detección de Rimas & $1^{\mathrm{o}}$ & 97 & 0,7975 & 1,00 & 0,311 \\
& $2^{\mathrm{o}}$ & 67 & 0,9615 & 1,00 & 0,069 \\
\cline { 2 - 6 } Adición Silábica & $1^{\mathrm{o}}$ & 97 & 0,9381 & 1,00 & 0,242 \\
\cline { 2 - 6 } Aislar Fonemas & $2^{\mathrm{o}}$ & 67 & 0,9343 & 1,00 & 0,121 \\
\cline { 2 - 6 } & $1^{\mathrm{o}}$ & 97 & 0,8405 & 1,00 & 0,281 \\
Unir Fonemas & $2^{\mathrm{o}}$ & 67 & 0,9170 & 1,00 & 0,148 \\
\cline { 2 - 6 } & $1^{\mathrm{o}}$ & 97 & 0,6299 & 0,65 & 0,274 \\
\cline { 2 - 6 } Contar Fonemas & $2^{\mathrm{o}}$ & 67 & 0,9142 & 1,00 & 0,122 \\
\cline { 2 - 6 } & $1^{\mathrm{o}}$ & 97 & 0,6778 & 0,7 & 0,295 \\
\cline { 2 - 6 } THM & $2^{\mathrm{o}}$ & 67 & 0,8336 & 0,8 & 0,138 \\
\hline & $1^{\mathrm{o}}$ & 97 & 5,5352 & 5,87 & 1,516 \\
\hline
\end{tabular}

De acuerdo con la Tabla 5, los alumnos de $2^{\circ}$ grado obtienen mayor promedio en todas las habilidades metalingüísticas, siendo las diferencias más notorias en unir fonemas y contar fonemas.

Tabla 6. Niveles habilidades metalingüísticas según grado de estudio

\begin{tabular}{cccccc}
\hline \multirow{2}{*}{ NIVEL } & \multirow{2}{*}{$\mathrm{N}$} & \multicolumn{2}{c}{ Frecuencia } & \multicolumn{2}{c}{ Porcentaje } \\
\cline { 3 - 6 } & & $1^{\mathrm{o}}$ & $2^{\mathrm{o}}$ & $1^{\mathrm{o}}$ & $2^{\mathrm{o}}$ \\
\hline DEFICIENTE & 164 & 5 & 0 & $5,2 \%$ & $0 \%$ \\
INTERMEDIO & 164 & 31 & 4 & $32,0 \%$ & $6,0 \%$ \\
AVANZADO & 164 & 61 & 63 & $62,9 \%$ & $94,0 \%$ \\
$\quad$ Total & 164 & 97 & 67 & $100,0 \%$ & $100,0 \%$ \\
\hline
\end{tabular}

De acuerdo con la Tabla 6 , los alumnos de $1^{\circ}$ grado $5,2 \%$ presentan nivel Deficiente $32,0 \%$ nivel Intermedio, y 62,9\% nivel Avanzado. En el caso de los alumnos de $2^{\circ}$ grado 6,0\% obtienen nivel Intermedio, y 94,0\% nivel Avanzado, siendo este último grupo el mayoritario. En ambos caso el nivel mayoritario es Avanzado. 
Relación entre las Habilidades Metalinguisticas y la Memoria en Niños de Primer y Segundo Grado de Primaria de Lima METROPOLITANA

\section{Resultados Inferenciales}

Tabla 7

Prueba de normalidad - Test de Kolmogorov Smirnov

\begin{tabular}{cccc}
\hline & \multicolumn{3}{c}{ Kolmogorov-Smirnova } \\
& Estadístico & gl & Sig. \\
\hline Dígitos Directo &, 169 & 124 &, 000 \\
\hline Dígitos Inverso &, 188 & 124 &, 000 \\
\hline Memoria Dígitos &, 159 & 124 &, 000 \\
\hline Segmentación Silábica &, 510 & 124 &, 000 \\
\hline Supresión Silábica &, 381 & 124 &, 000 \\
\hline Detección de Rimas &, 419 & 124 &, 000 \\
\hline Adición Silábica &, 426 & 124 &, 000 \\
\hline Aislar Fonemas &, 301 & 124 &, 000 \\
\hline Unir Fonemas &, 182 & 124 &, 000 \\
\hline Contar Fonemas &, 198 & 124 &, 000 \\
\hline THM &, 232 & 124 &, 000 \\
\hline
\end{tabular}

De acuerdo con la Tabla 7, se observa el estadístico de Kolmogorov Smirnov en todos los casos obtienen niveles de significación de 0,000 . Puesto que el valor es menor que 0,05 , rechazamos la hipótesis de normalidad y concluimos que las puntuaciones no se ajustan a una distribución normal. De acuerdo a esto se decide el uso de estadísticos no paramétricos.

Tabla 8. Coeficientes de correlación Rho de Spearman

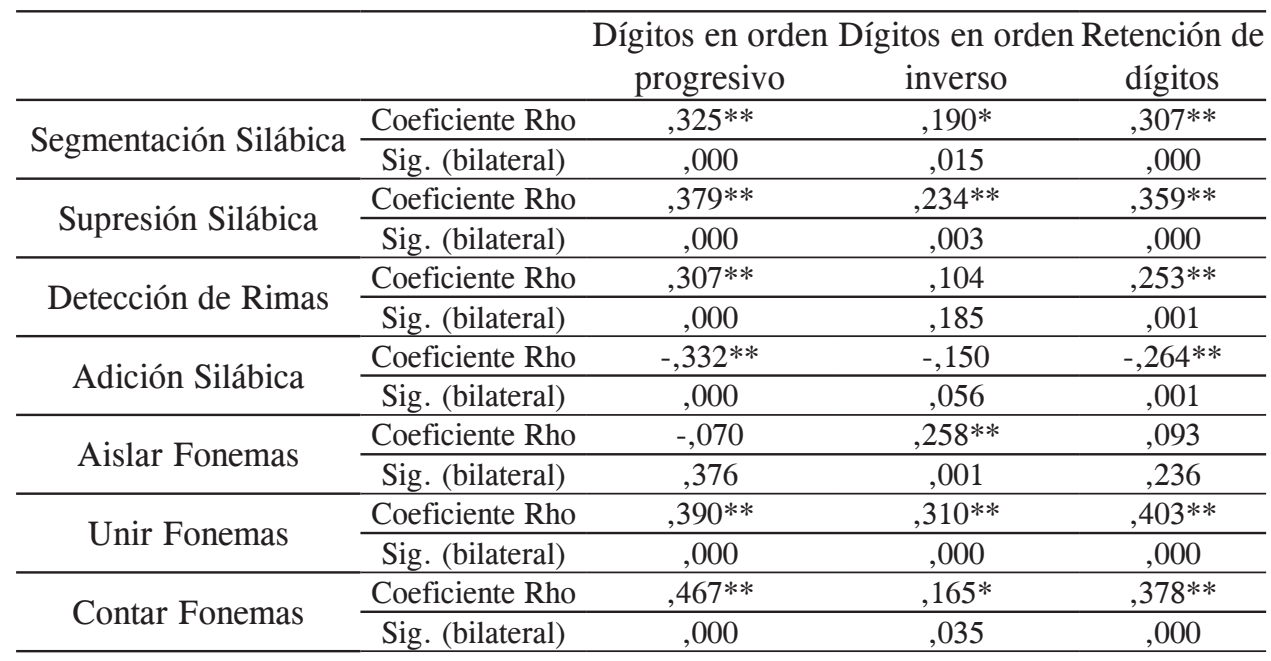

**. La correlación es significativa al nivel 0,01 (bilateral).

* . La correlación es significativa al nivel 0,05 (bilateral). 
De acuerdo con la Tabla 8, se encuentran correlaciones positivas significativas entre la retención de dígitos en orden progresivo con segmentación silábica $(\mathrm{Rho}=0,325)$, supresión silábica $(\mathrm{Rho}=0,379)$, detección de rimas $(0,307)$, unir fonemas $(\mathrm{Rho}=0,390)$ y contar fonemas $(\mathrm{Rho}=0,467)$, por el contrario presenta correlación negativa significativa con adición silábica $(\mathrm{Rho}=0,332)$. En el caso de retención de dígitos en orden inverso se presentan correlaciones positivas con segmentación silábica $(\mathrm{Rho}=0,190)$, supresión silábica $(\mathrm{Rho}=0,234)$, aislar fonemas $(\mathrm{Rho}=0,267)$ y contar fonemas $(\mathrm{Rho}=0,165)$. Finalmente en el caso de retención de dígitos se encuentran correlaciones positivas con todas las habilidades metalingüísticas a excepción de aislar fonemas.

Tabla 9. Coeficientes de correlación Rho de Spearman

\begin{tabular}{ccccc}
\hline & & $\begin{array}{c}\text { Dígitos en orden } \\
\text { progresivo }\end{array}$ & $\begin{array}{c}\text { Dígitos en orden } \\
\text { inverso }\end{array}$ & $\begin{array}{c}\text { Retención de } \\
\text { dígitos }\end{array}$ \\
\hline \multirow{2}{*}{ THM } & Coeficiente Rho &, $446^{* *}$ &, $315^{* *}$ &, $442^{* *}$ \\
\cline { 2 - 5 } & Sig. (bilateral) &, 000 &, 000 &, 000 \\
\hline
\end{tabular}

De acuerdo con la Tabla 9, se encuentran correlaciones positivas significativas entre la retención de dígitos en orden progresivo, dígitos en orden inverso y retención de dígitos con las habilidades metalingüísticas en niños de $1^{\circ}$ y $2^{\circ}$ grado de primaria.

Tabla 10. Diferencia de medias en habilidades metalingüísticas, según grado de estudio

\begin{tabular}{cccccccc}
\hline & $\begin{array}{c}\text { Segmentación } \\
\text { Silábica }\end{array}$ & $\begin{array}{c}\text { Supresión Detección } \\
\text { Silábica }\end{array}$ & $\begin{array}{c}\text { Adición } \\
\text { de Rimas }\end{array}$ & $\begin{array}{c}\text { Aislar } \\
\text { Silábica }\end{array}$ & $\begin{array}{c}\text { Enir } \\
\text { Fonemas }\end{array}$ & $\begin{array}{c}\text { Contar } \\
\text { Fonemas Fonemas }\end{array}$ \\
\hline $\begin{array}{c}\text { U de Mann- } \\
\text { Whitney }\end{array}$ & 2453,000 & 1865,000 & 2699,500 & 2495,000 & 2727,500 & 1098,500 & 2199,000 \\
\hline $\begin{array}{c}\text { W de } \\
\text { Wilcoxon }\end{array}$ & 7206,000 & 6618,000 & 7452,500 & 4773,000 & 7480,500 & 5851,500 & 6952,000 \\
\hline Z & $-3,852$ & $-5,319$ & $-2,133$ & $-3,910$ & $-1,995$ & $-7,326$ & $-3,560$ \\
\hline $\begin{array}{c}\text { Sig. } \\
\text { (bilateral) }\end{array}$ &, 000 &, 000 &, 033 &, 000 &, 046 &, 000 &, 000 \\
\hline
\end{tabular}

La Tabla 10, presenta el estadístico U de Mann-Whitney, además la tipificación (Z), y el nivel crítico bilateral (Sig.) es menor a 0,05 en todos los casos examinados. Esto indica que existen diferencias significativas habilidades metalingüísticas según el grado de estudio, lo cual permite concluir que el grado de estudio influye en la habilidad metalingüística.

Tabla 11. Diferencia de medias en habilidades metalingüísticas (promedio total), según grado de estudio

\begin{tabular}{lc}
\hline & THM \\
\hline U de Mann-Whitney & 1459,500 \\
\hline W de Wilcoxon & 6212,500 \\
\hline$Z$ & $-6,000$ \\
\hline Sig. (bilateral) &, 000 \\
\hline
\end{tabular}


Relación entre las Habilidades Metalinguisticas y la Memoria en Niños de Primer y Segundo Grado de Primaria de Lima Metropoltana

La Tabla 11, presenta el estadístico U de Mann-Whitney, además la tipificación (Z), y el nivel crítico bilateral (Sig.) es menor a 0,05 en el caso de la habilidad metalingüística. Esto indica que existen diferencias significativas en la habilidad metalingüística (total) según el grado de estudio, lo cual permite concluir que el grado de estudio influye en la habilidad metalingüística.

Tabla 12. Diferencia de medias en retención de dígitos, según grado de estudio

\begin{tabular}{cccc}
\hline & $\begin{array}{c}\text { Dígitos } \\
\text { en orden } \\
\text { progresivo }\end{array}$ & $\begin{array}{c}\text { Dígitos en } \\
\text { orden inverso }\end{array}$ & $\begin{array}{c}\text { Retención de } \\
\text { dígitos }\end{array}$ \\
\hline U de Mann-Whitney & 561,000 & 770,000 & 310,000 \\
\hline W de Wilcoxon & 5314,000 & 5523,000 & 5063,000 \\
\hline Z & $-9,185$ & $-8,492$ & $-9,892$ \\
\hline Sig. (bilateral) &, 000 &, 000 &, 000 \\
\hline
\end{tabular}

La Tabla 12, presenta el estadístico U de Mann-Whitney, además la tipificación (Z), y el nivel crítico bilateral (Sig.) es menor a 0,05 en el caso de la habilidad metalingüística. Esto indica que existen diferencias significativas en retención de dígitos, así como en retención en orden progresivo y orden inverso, según el grado de estudio, lo cual permite concluir que el grado de estudio influye en la habilidad metalingüística.

Figura 1. Regresión simple entre Memoria (Eje X) y

Habilidades metalingüísticas (Eje Y)

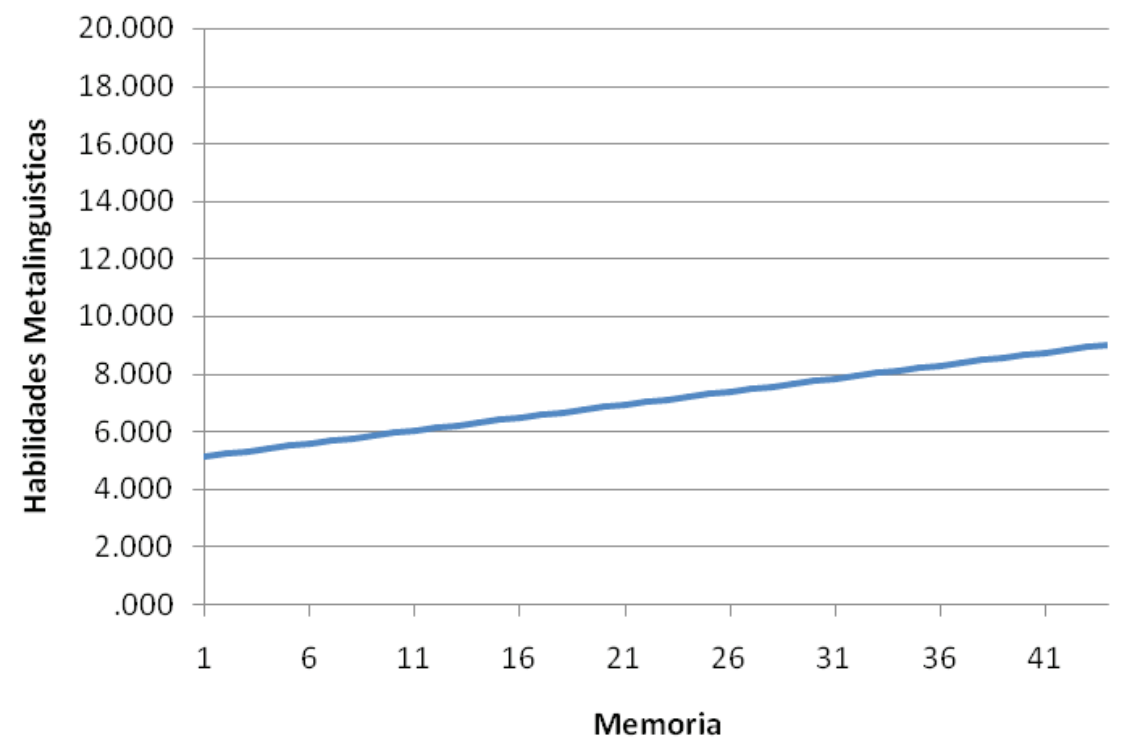




\begin{tabular}{|c|c|}
\hline Formula & $\mathrm{Y}=\mathrm{a}+\mathrm{b} \mathrm{x}$ \\
\hline Constante & $\mathrm{a}=5,059$ \\
\hline Pendiente & $\mathrm{b}=0,090$ \\
\hline
\end{tabular}

De acuerdo con la figura 1, al realizar el análisis de regresión se observa que al considerar las habilidades metalingüísticas estas se incrementan al mejorar la capacidad de retención de dígitos, siendo importante en específico la retención progresiva de dígitos. Observándose que los niños de 6 años presentan un rendimiento constantes de retención de 5 dígitos.

\section{DISCUSIÓN}

Teniendo en cuenta los resultados obtenidos se evidencia la relación directa entre las habilidades metalingüísticas y la memoria explorada a través de la retención de dígitos (Véase tablas 8 y 9). Esto podría indicar que la memoria se constituiría en un factor importante en las habilidades metalingüísticas y la conciencia fonológica, y dado que la conciencia fonológica está referida al conocimiento de las unidades de sonido (fonemas) usados en un lenguaje (Gimeno, 1993), incluyendo la habilidad de oír fonemas separados. Dado que este conocimiento exige el reconocimiento de las palabras las cuales están compuestas de unidades de sonido y que las unidades de sonido pueden ser combinadas para formar palabras (Mayer 2002), pero este reconocimiento implica una capacidad de retener, o un proceso de almacenamiento y recuperación de la información (citar). Para Baddeley (1992) esta capacidad se refiere a la memoria a corto plazo, pues es la que guarda y procesa durante breve tiempo la información que viene de los registros sensoriales y actúa sobre ellos y también sobre otros. Por lo tanto podríamos considerar que la capacidad de retención permite ejecutar operaciones cognitivas básicas para los mecanismos de percepción del habla, que permitirían establecer la relación entre las letras del alfabeto y los sonidos y/o fonemas que representan (Gimeno, 1993) y reconocer una unidad fonológica del lenguaje hablado (Amaiz y Ruiz, 2001).

Al considerar a las habilidades metalingüísticas, como la capacidad que posee el niño de la estructura y funciones de su lengua, permitiéndole diferenciar la naturaleza de las palabras y frases en los ámbitos fonológico, semántico, sintáctico y pragmático, esto se acerca al planteamiento de Baddeley y Hitch (1974) sobre memoria de trabajo, los cuales al asignar a un grupo de sujetos que realizaran una tarea que exigiera la utilización de gran parte de la capacidad de la memoria de trabajo (amplitud de memoria de dígitos) y en el mismo momento, le pidieron que realizara otra tarea que supuestamente dependía también de la memoria de trabajo (una tarea de aprendizaje). Encontraron que el tiempo necesario para realizar la tarea de aprendizaje aumentó de forma sistemática en función del aumento de la carga de memoria impuesta por la tarea de repetición de dígitos; esta actividad es similar a las realizada por niños en las habilidades metalingüísticas pues se les asigna tareas como segmentación de silabas, supresión de silabas, detección de rimas, adición de silabas, aislar los fonemas, unir fonemas y contar fonemas, 
pues en todas ellas el niño debe reconocer los sonidos, dividirlos en unidades, reconstruirlos y organizarlos según los objetivos de las tareas pedidas. Todo este proceso requiere como función cognitiva básica el retener los sonidos en un almacén de sonidos, esto es lo que Baddeley y Hitch (1974) propusieron como modelo de la memoria a corto plazo, pues en vez de ser una memoria unitaria, estaba formada por un ejecutivo central que desempeña el papel del control atencional y dos sistemas subsidiarios, el bucle articulatorio encargado de conservar transitoriamente la información auditiva y estaría relacionado con el tratamiento de los contenidos del lenguaje oral y la agenda visoespacial que sería el encargado de la conservación transitoria de la información visoespacial y el procesamiento de las imágenes mentales.

Este modelo de la memoria permite explicar las diferencias en la relación de las habilidades metalingüísticas y la retención, pues en primera instancia la relación es más alta en el caso de retención progresiva de dígitos, lo que indicaría su importancia para poder mantener en el bucle fonológico la información auditiva y realizar tareas de detección, segmentación, supresión, adición y conteo de sonidos, pero no se relaciona con aislar fonemas, lo cual se debería a que en esta operación se exige descomponer la palabras en unidades fonemicas y ubicar un fonema en distintas posiciones, lo que supone tareas correspondientes a ubicar espacialmente dentro de la palabra a este fonema; por su parte, la retención de dígitos implica trabajo con unidades aisladas sin una relación en conjunto.

El caso de las diferencias observadas en las habilidades metalingüísticas y de retención de dígitos, en función del grado de estudio se condice con los hallazgos de Gutierrez, et al. (2002) quienes desarrollaron una investigación longitudinal de la memoria operativa desde los 6 años hasta la edad adulta, utilizando distintos tipos de tareas: memoria a corto plazo, memoria operativa, de reconocimiento de palabras y de comprensión lectora. Los resultados mostraron un crecimiento gradual en el desarrollo de la memoria operativa desde los 6 hasta los 19 años y una disminución tambien gradual a partir del final de la adolescencia, con una mayor caida a partir de los 65 y 70 años. En nuestro estudio los alumnos de grados superiores, logran mejores rendimientos en las habilidaes metalinguisticas y la mermoria. De este modo al hacer el analisis de regresion se pudo establecer que los niños de 6 años presentan una amplitud de 5 dígitos, como capacidad en retención con base en la memoria, y que el aumento de esta capacidad de retención influiría en el incremento gradual de la habilidad metalingüística.

\section{CONCLUSIONES}

1. Existe relación entre las habilidades metalingüísticas y la memoria en niños de primer y segundo grado de primaria.

2. Se encuentran correlaciones positivas entre la retención de dígitos en orden progresivo con segmentación silábica, supresión silábica, detección de rimas, unir fonemas y contar fonemas. 
3. Se presenta correlación negativa significativa entre retención de dígitos en orden progresivo con adición silábica.

4. En el caso de retención de dígitos en orden inverso se presentan correlaciones positivas con segmentación silábica, supresión silábica, aislar fonemas y contar fonemas.

5. En el caso de retención de dígitos general se encuentran correlaciones positivas con todas las habilidades metalingüísticas a excepción de aislar fonemas.

6. Existen diferencias en las dimensiones de las habilidades metalingüísticas según el grado de estudio.

7. Existen diferencias en la habilidad metalingüística (total) según el grado de estudio.

8. Existen diferencias en retención de dígitos total, así como en retención en orden progresivo y orden inverso, según el grado de estudio.

\section{REFERENCIAS BIBLIOGRAFICAS}

Baddeley, A. (1992) Working Memory. Science, New Series, Vol. 255, No. 5044. (Jan. 31, 1992), pp. 556-559.

Baddeley, A. D., \& Hitch, G. (1974). Working memory. In K.W. Spence and J. T. Spence (eds.) The Psychology of Learning and Motivation, vol 8. (pp. 67-89). New York: Academic Press.

Ballesteros, S. (1999) Memoria Humana: Investigación y Teoría. Psicothema, Vol. 11, $\mathrm{N}^{\mathrm{o}} 4$, pp. 705-723.

Calero, A.; Pérez, R. Maldonado, A. y Sebastián, M. (1999) Materiales curriculares para favorecer el acceso a la lectura en educación infantil. Barcelona: Praxis.

Canales, R. (2003) Conciencia fonológica y lectura: el nuevo enfoque psicolinguistico en los problemas de aprendizaje. En Revista de Psicología. Año VI, 1, abril 2003.

Condemarin, M (1989) Lectura temprana. Santiago de Chile: Andres Bello.

Crespo, N. y Alvarado, C. (2010) Conciencia metapragmática y memoria operativa en niños escolares. Literatura y lingüística. Vol 21. pp 93-108.

Cuetos, F. (1999) Psicología de la lectura. Madrid: Escuela Española

Dioses (2004) Memoria auditiva inmediata y dificultades ortográficas en niños de 5to y 6to grado de educación primaria de colegios de Lima. Centro de Investigaciones y publicaciones CPAL.

Ellis, N.C., \& Sinclair, S.G. (1996). Working memory in the acquisition of vocabulary and syntax: Putting language in good order. Quarterly Journal of Experimental psychology, 49A. p. 234- 250.

Gárate, M.; Luque, J.; Gutiérrez, F.; Elosúa, M. y García, J. (1997) Un estudio sobre las diferencias evolutivas en la memoria operativa: ¿capacidad o eficiencia? Estudios de psicología, $\mathrm{N}^{\mathrm{o}} 58,1997$, pags. 15-28

García, A.; Canet, L. y Andres, M. (2010) Desarrollo de la flexibilidad cognitiva y de la memoria de trabajo en niños de 6 a 9 años de edad. Revista Mexicana de Investigación 
Relación entre las Habilidades Metalinguisticas y la Memoria en Niños de Primer y Segundo Grado de Primaria de Lima Metropoltana

en Psicología. Vol 2, $\mathrm{N}^{0} 1$, pp 12-19.

Gimeno, A. (1993). La conciencia fonológica en el aprendizaje de la lectura: Bases para la elaboración de un instrumento de medida. Revista de Psicología de la Educación. Volumen 4, 12.

Gonzáles, M. y Romero, J. (1999) ¿Influye el desarrollo de la producción fonológica en el aprendizaje de la lectura? Revista Logopedia, Foniatría y Audiología Vol19,1.

Gutierrez, F.; Garcia Madruga, J.; Elosua, R.; Luque, J y Gárate, M.(2002) Memoria operativa y comprensión lectora: algunas cuestiones básicas. Acción psicológica. Vol 1, pp. 45-68

Introzzi, I.; Canet , L. y Andrés, M. (2010) Desarrollo de estrategias de memoria en niños de 5 a 8 años de edad . Revista Mexicana de Psicología, vol. 27, núm. 2, 2010, pp. 117-125

Jiménez, J y Ortiz, M. (2000) Conciencia fonológica y aprendizaje de la lectura: teoría, evaluación e intervención. Madrid: Síntesis.

Vidal, J. y Manjón, D. (2000) Dificultades de aprendizaje e intervención psicopedagógica: lectura y escritura. Madrid: EOS

Matalinares, M y Diaz, G. (2007) Habilidades metalinguísticas y comprensión en niños de Primer grado de las ciudades de Lima y Huancayo. Revista de Psicología Vol 9, pp 60-71 Trujillo.

Matalinares, M.; Dioses, A.; Arenas, I.; Diaz, G. , Chávez,J., Yaringaño, J. y Suárez, J. (2007) Lenguaje comprensivo y memoria auditiva inmediata en estudiantes de $5 .^{\circ}$ y6 ${ }^{\circ}$ grado de primaria de zona rural y urbana de Lima. Revista de Investigación en Psicología Vol. 10 - No 2 pp71-83.

Mayer, R.(2002) Psicología de la educación: el aprendizaje en las área de conocimiento. New Jersey: Prentice Hall.

Molina, S. (1981) Enseñanza y aprendizaje de la lectura. Madrid: CEPE.

Noriega, E. (1998) Estudio cualitativo de los niveles de comprensión lectora de un grupo de niños deficientes y buenops lectores antes y despues del programa de intervencion. tesis para optar grado Doctor UNMSM.

Pino, M. y Bravo, L. (2005) La Memoria Visual Como Predictor del Aprendizaje de la Lectura. PSYKHE Vol 14, $\mathrm{N}^{\circ} 01,47-53$.

Rodríguez, M. (2003). Las habilidades metalingüísticas en alumnos del tercer grado de primaria de colegio estatal y particular. Lima: Universidad Ricardo Palma Tesis psicología.

Sáiz, D. y Baqués, J (1999) Medidas simples y compuestas de memoria de trabajo y su relación con el aprendizaje de la lectura Psicothema, Vol. 11, $\mathrm{N}^{\mathrm{o}}$. 4, pags. 737-745 